\title{
The stress levels of parents of premature infants and related factors in Nenoatal Intensive Care Units
}

\author{
Burcu Çekin ${ }^{1}$, Türkan Turan ${ }^{2}$ \\ ${ }^{1}$ Neonatal Intensive Care Unit, Süleyman Demirel University Faculty of Medicine, Isparta; ${ }^{2}$ Pediatric Nursing Department, \\ Pamukkale University Faculty of Health Science, Denizli. Turkey. \\ E-mail: turkanturan@pau.edu.tr \\ Received: 19th April 2017, Revised: 19th June 2017, 10th August 2017, 19th September 2017, \\ Accepted: 30th October 2017
}

SUMMARY: Çekin B, Turan T. The stress levels of parents of premature infants and related factors in Nenoatal Intensive Care Units. Turk J Pediatr 2018; 60: 117-125.

The aim of this study is to determine the stress levels of parents whose premature baby are hospitalized in the neonatal intensive care unit (NICU) and to determine the factors affecting their stress. The study sample included 101 parents of premature babies in the NICU of a university hospital. Interviews were conducted with the parents. Additionally, the Parental Stress Scale: Neonatal Intensive Care Unit (PSS:NICU) was administered.

When the stress levels of parents in the NICU were analyzed, it was found that their scores on the infant's appearance and behaviors subscale of the PSS:NICU reflected the highest rate of stress. The mean score on the parental role alterations subscale was higher among mothers than fathers $(p<0.05)$. Additionally, high stress levels were found among parents who had children other than their baby in the NICU, parents whose baby had a young gestation age and a low birthweight, parents whose baby was on a respiration device, and parents who had experienced a stressful event in the past year. The stress levels of parents whose premature baby was hospitalized in the NICU were also high. The family-centred approach is recommended to identify and meet all the needs of all such parents.

Key words: NICU, premature baby, parents, stress level.

Approximately 15 million infants worldwide are born before the 37 th week of gestation in other words, prematurely. ${ }^{1}$ This number is gradually increasing. Approximately 1 million children die every year due to complications arising from premature birth. Babies who survive often live with problems such as learning disabilities, vision and hearing problems. ${ }^{2}$

During pregnancy, families develop expectations for their future babies according to their prior experience. However, premature birth may adversely affect such expectations. Parents with a premature infant can find themselves in a strange, advanced technological environment ${ }^{3-4}$. It is an unexpected experience and extremely stressful for parents to have a premature infant and to have their babies treated in a neonatal intensive care unit. ${ }^{5-7}$ Their stress originates from the premature birth, the environment of the neonatal intensive care unit, changes in parental role perception, the health status of the mother and baby after birth and dependence on healthcare professionals. ${ }^{8-10}$ Parents with infants hospitalized in neonatal intensive care experience shock, doubt, frustration, guilt, sadness, depression, hostility, anger, fear, anxiety, grief, despair, feelings of failure and loss of self-esteem. ${ }^{11-14}$ Studies conducted on mothers with infants hospitalized in neonatal intensive care units in Turkey have reported similar results. ${ }^{4,15,16}$

Having a premature baby is stressful. Parents may struggle to address the stresses and concerns they experience in different ways. Providing parents with support should be an integral part of neonatal intensive care units. ${ }^{17}$ Parents should be provided with support through family-centered care in these units. 
Family-centered care acknowledges family continuity in a baby's life. Nurses and parents should provide the best joint care to ensure babies are healthy. Nurses should establish a therapeutic relationship with parents and address their needs; they should identify the factors increasing the stress levels of parents and provide parents with necessary information. For example, monitor sounds may negatively affect parents; if nurses provide parents with information about monitor alarms and adjust alarm limits at appropriate intervals, the stress levels of parents may decrease. In addition, providing parents with explanations of the medical interventions used for their baby will reduce parents' stress levels caused by uncertainty and increase their participation in treatment. ${ }^{18}$

The PSS:NICU was developed to assess the stress levels of parents with premature infants hospitalized in intensive care units. ${ }^{19}$ In the scale, there were items for sources of stress that were considered to be experienced by parents whose premature babies were hospitalized in neonatal intensive care unit. Many studies were found in the literature which were performed by using this scale. ${ }^{6,18,20,21,23,24}$ There are two studies in our country using this scale., ${ }^{4,22}$ Physical conditions such as the light, noise, and sounds made by technological tools in neonatal intensive care units as well as the appearance and behaviors of babies cause stress among parents. However, recent studies show that the factor that causes stress most frequently is the loss of the expected parental role. ${ }^{4,25}$ Identifying sources of stress is the best method to better understand and protect parents. Parents should be provided with the conditions necessary to allow them to be close to their babies in neonatal intensive care units. Nurses should minimize mother-baby separation as much as possible by providing a suitable environment. ${ }^{17,26}$

\section{Material and Methods}

The data in this study was collected in the neonatal intensive care unit of a university hospital located in western Turkey. The sample consisted of parents of premature infants hospitalized in this neonatal intensive care unit between March 2012 and May 2013. The smallest possible sample size was found to be 100 parents, with a confidence level of
$95 \%$ and a power of $80 \%$, as indicated by the power analysis performed. ${ }^{27}$ The sample included 101 parents of premature infants who were born at a gestation age of 24 to 37 weeks, did not undergo any surgery and had not been in the NICU for more than 5 to 10 days at the time of the data collection. The data was collected using a face-to-face interview technique and a questionnaire form. Parents were informed by researchers about the study and its objective before the study commenced, and the consent of the parents was obtained. Parents were subsequently asked to complete the questionnaire forms within 30 minutes.

\section{Parental Stress Scale: Neonatal Intensive Care Unit (PSS:NICU)}

The PSS:NICU was developed by Miles et al. ${ }^{19}$ to determine parents' perceived levels of stress resulting from the physical and psychosocial environment of neonatal intensive care units in 1993. This scale must be administered to parents who are literate because it is a self-report scale. In the original study in which PSS:NICU was developed, the scale was performed to the parents within the first week after their babies were hospitalized in NICU. If the condition of the baby was not stable or the parents were highly stressed, interview was postponed ${ }^{19}$. There are intervention studies in which scale was performed to the parents following hospitalization of the premature baby. ${ }^{28,29,30}$

The scale has three subscales: sights and sounds, infant's appearance and behaviors and parental role alteration. Parents were asked to rate their stress level in relation to each variable on a scale between 1 (not stressful) and 5 (extremely stressful). Parents infants who were without symptoms - such as problems that would require tubes and other equipment on or next to them, sudden changes in colour or respiratory arrest - left blank the relevant items on the scale when completing the questionnaire. The data was analyzed using the SPSS 18.0 program.

Turkish validity and reliability study was carried out with parents whose premature babies were hospitalized in neonatal intensive care unit in 2006. ${ }^{31}$ Cronbach's alpha coefficient was found to be 0.89 , according to the results of the first assessment of the PSS:NICU, and 0.90 , according to the results of the second 
assessment of the same scale. Cronbach's alpha reliability coefficients were found to be quite high on both assessments. A factor analysis of the structural validity of the PSS:NICU was performed by principal component analysis with varimax rotation. As a result, 13 items were found for factor I (item loadings between 0.42 and 0.75), 10 items for factor II (item loadings between 0.45 and 0.74 ), and 6 items for factor III (item loadings between 0.38 and 0.84). The factor structure of the scale did not differ from the original structure. The testretest correlation coefficient of the PSS:NICU was found to be 0.58 for the total scale and 0.44 and 0.60 for the subscales, respectively. ${ }^{31}$

The written consent of the Ethics Committee and the University Hospital was obtained to conduct the study. All parents enrolled in the study were informed about the study and its objective, and their verbal consent was obtained prior to the administration of the data collection forms.

\section{Results}

Within the sample, $31.7 \%$ of the parents were aged 20 to 29 years, $37.6 \%$ were primary school graduates, $37.6 \%$ were high school graduates, and $14.9 \%$ were university graduates. Additionally, $34.7 \%$ of the parents were employed, and $60.4 \%$ had one child. Twenty percent of the parents had experienced stressful events in the past year. Regarding the infants, $57.4 \%$ were male and $42.6 \%$ female; $11.9 \%$ were born between 24 and 28 weeks of gestation, $23.8 \%$ between 29 and 32 weeks of gestation, and $64.3 \%$ between 33 and 37 weeks of gestation; $33.7 \%$ weighed $1500 \mathrm{~g}$ or less, and $66.3 \%$ weighed above $1500 \mathrm{~g}$. Additionally, $46.5 \%$ of the infants enrolled in the study were hospitalized in the neonatal intensive care unit for 5 to 7 days and $53.5 \%$ for 8 to 10 days; $32.7 \%$ of the infants were connected to respiratory equipment (Table I).

The overall mean scores of the parents on the PSS:NICU and its subscales are shown in Table II. The mean score on the sights and sounds subscale was $3.03 \pm 1.03$; the mean score on the infant's appearance and behaviours subscale was $3.53 \pm 1.16$; the mean score on the parental role alterations subscale was $2.90 \pm 1.23$; and the overall mean score was 3.23 \pm 0.98 (Table II). No statistically significant difference was found between the total stress scores of the mothers and fathers in the examination of the total mean stress scores $(p>0.05)$. However, it was found that the mothers' mean stress scores were higher than the fathers' mean stress scores (Table III). A statistically significant difference was found between total scores of the parents on the PSS:NICU in terms of the number of living children of the parents $(p<0.05)$. Stress levels of parents with children other than the infants hospitalized in the intensive care unit were higher than those of parents with no other children. A statistically significant difference was found in the total scores of the parents on the PSS:NICU and their infant's need for respiratory support $(\mathrm{p}<0.05)$. Parents of infants connected to respiratory equipment experienced a higher level of stress than parents of infants breathing normally. No statistically significant difference was found between total scores of the parents on the PSS:NICU in terms of age, level of education, the experience of stressful events in the past year, frequency of visits and knowledge acquisition ( $p>0.05)$. No statistically significant difference was found between total scores on the PSS:NICU in terms of gestational age, birth weight, or number of days from birth $(\mathrm{p}>0.05)$ (Table IV).

\section{Discussion}

Determining stress levels experienced by parents of premature infants hospitalized in neonatal intensive care units is crucial for healthcare professionals working in intensive care units. Determining the factors that cause stress among parents and developing appropriate intervention protocols will help reduce the stress levels of parents and give parents the ability to cope with the complex neonatal intensive care environment. ${ }^{4}$

When examining the mean scores of the PSS:NICU subscales, the highest mean score belongs to the subscale of the infant's appearance and behaviors (3.53), followed by the sights and sounds subscale mean score (3.03) and then the parents' role alterations subscale mean score (2.90). Based on the results, it was determined that the area that causes the most stress for parents is their infant's appearance and behaviors. This result was similar to the finding of Shields-Poe and Pinelli32, who performed a study of 212 parents using the PSS:NICU and determined 
Table I. Baseline Characteristics of Parents and Their Preterm Infants.

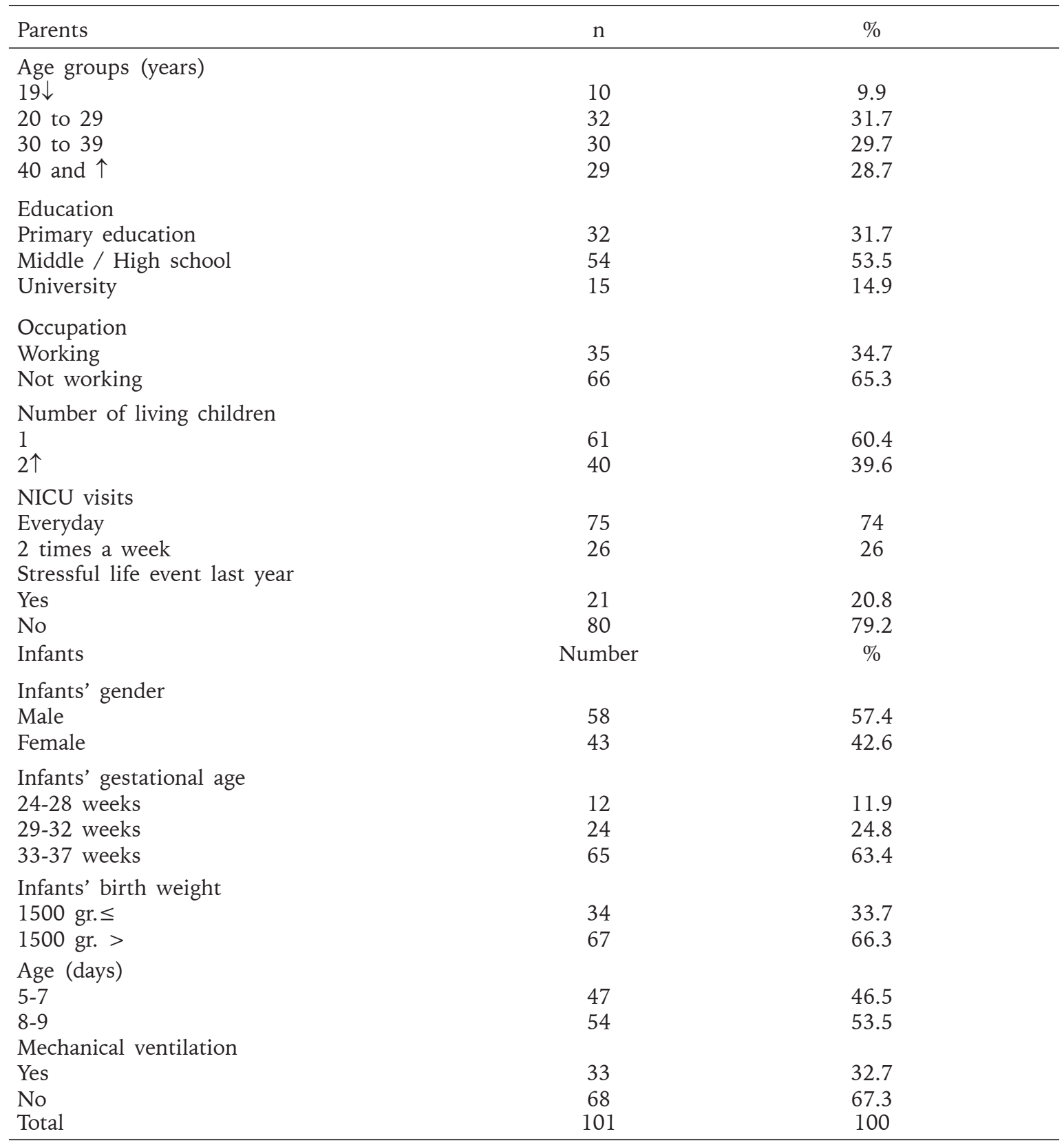

that the parents' greatest stress was due to their infant's appearance and behaviors. In a study conducted by Preyda and Ardal ${ }^{33}$, treatment group parents' mean score on the infant's appearance and behaviors subscale was found to be 3.40 , and the mean score of the control group parents was found to be 3.56 . The mean scores in their study are similar to those in our study, but different from our study, Preyda and Ardal ${ }^{33}$ determined that the factor that creates the most stress for parents is parental role alterations.

Other studies in the literature have found that mean scores of parents on the infant's appearance and behaviours subscale of the PSS:NICU were lower than those in our study. ${ }^{20,21}$ This subscale primarily focuses on infants' appearance and behaviours. The physical appearance of premature infants (thin, transparent skin, very big head) is different than 
Table II. Parents' Total and Subscales' Mean Scores $(n=101)$.

\begin{tabular}{lcc}
\hline PSS:NICU & Mean & S.D \\
\hline Sights and sounds & 3.03 & 1.03 \\
Infant's appearance and behaviors & 3.53 & 1.16 \\
Parental role alteration & 2.90 & 1.23 \\
Total & 3.23 & 0.98 \\
\hline
\end{tabular}

PSS:NICU: parental stressor scale: neonatal intensive care unit

SD: standard deviation

babies born at full term, and they are often on ventilators; therefore, they require more sedation, which causes a reduction in physical response. ${ }^{34}$ Montirosso et $\mathrm{al}^{21}$ indicated that stress levels of parents decreased after they observed their baby's behaviors; otherwise, they needed more emotional support, although there were no clinical complications with their infant. The levels of stress experienced by parents can be reduced by providing parents with information on the normal appearance and prevalent physical behaviors of premature infants.

Parents' mean score on the sights and sounds subscale was found to be 3.03 in the study, which is higher than the scores found in other studies using the PSS:NICU.20,21,33 In a study conducted in our country, the mean score on the sights and sounds subscale of the PSS:NICU was found to be $2.08 .^{22}$ Such high levels of stress can be reduced by using the Newborn Individualized Developmental Care and Assessment Program (NIDCAP) principles. These principles include noise, light and nursing care activities that allow for more favorable development of infants and changes in the physical environment. The American Academy of Pediatrics recommends that the average light intensity in neonatal intensive care units be 646 Lux and that noise levels be reduced below $50 \mathrm{~dB}$ during the day and $35 \mathrm{~dB}$ at night. ${ }^{35}$ Knowledge of stress-related environmental resources can help nurses reduce parents' levels of stress. For example, when parents are informed about the reasons for the use of monitors in neonatal intensive care units and when monitor alarm sound levels are adjusted to appropriate levels, the stress experienced by parents in this regard will decrease.
Parents' mean score on the parental role subscale was 2.90. In a study conducted with British mothers by Franck et al. ${ }^{20}$, the mean score on the parental role subscale was found to be 2.88. This mean score was found to be 2.61 among American parents. Similar to the study of Franck et al. ${ }^{20}$, in other studies using the PSS:NICU, the area that causes the most stress for parents in the NICU is parental role alterations. ${ }^{20,21,36}$ In Turkey, in the study of Turan et al. ${ }^{22}$, it was determined that parental role alterations cause the highest stress among parents. Parents state that they are not able to fulfil their roles in neonatal intensive care units and want to be given an opportunity to do so. In addition, parents want to know that healthcare personnel accept their baby as an individual and endeavour to give their baby the best treatment possible ${ }^{37}$. Healthcare personnel working in neonatal intensive care units must provide parents with support from the time their baby is hospitalized in the unit. ${ }^{21}$

In a study carried out by Preyda and Ardal ${ }^{33}$, they evaluated the effectiveness of parentto-parent peer support for mothers of very preterm infants in a neonatal intensive care unit, the total mean scores PSS:NICU of the study group and control group parents were found to be 3.18 and 3.28, respectively. Parents' total mean score on the PSS:NICU was found to be 3.23 in our study. The mean scores of the PSS:NICU in their study are similar to those in our study.

Other studies using the PSS:NICU have found that stress level of parents at the NICU is lower than in our study ${ }^{8,20,23}$. The hospitalization of infants in neonatal intensive care units happens suddenly, and parents do not have time to prepare for this experience. If any prenatal complication is found during examinations, 
Table III. Comparison of Stress Scores of Parents of Preterm Infants.

\begin{tabular}{|c|c|c|c|c|c|}
\hline Subscales of PSS:NICU & $\mathrm{n}$ & Mean (SD) & $95 \% \mathrm{CI}$ & $\begin{array}{l}\text { " t " } \\
\text { value }\end{array}$ & $\mathrm{p}$ \\
\hline \multicolumn{6}{|l|}{ Sights and sounds } \\
\hline $\begin{array}{l}\text { Mothers } \\
\text { Fathers }\end{array}$ & $\begin{array}{l}83 \\
18\end{array}$ & $\begin{array}{l}18.43(6.63) \\
19.05(4.39)\end{array}$ & $-3.87-2.63$ & -0.37 & $\begin{array}{l}0.08 \\
p>0.05\end{array}$ \\
\hline $\begin{array}{l}\text { Infant's appearance and } \\
\text { behaviors } \\
\text { Mothers } \\
\text { Fathers } \\
\text { Parental role alterations }\end{array}$ & $\begin{array}{l}83 \\
18\end{array}$ & $\begin{array}{l}62.66(18.2) \\
61.05(14.8)\end{array}$ & $-7.48-10.69$ & 0.35 & $\begin{array}{l}0.41 \\
p>0.05\end{array}$ \\
\hline $\begin{array}{l}\text { Mothers } \\
\text { Fathers }\end{array}$ & $\begin{array}{l}83 \\
18\end{array}$ & $\begin{array}{l}33.53(13.7) \\
33.50(8.97)\end{array}$ & $-6.72-6.78$ & 0.00 & $\begin{array}{l}0.02 \\
p<0.05\end{array}$ \\
\hline \multicolumn{6}{|l|}{ Total PSS:NICU } \\
\hline $\begin{array}{l}\text { Mothers } \\
\text { Fathers }\end{array}$ & $\begin{array}{l}83 \\
18\end{array}$ & $\begin{array}{l}114,62(32.4) \\
113,61(23.2)\end{array}$ & $-15.02-17.06$ & 0.12 & $\begin{array}{l}0.09 \\
p>0.05\end{array}$ \\
\hline
\end{tabular}

PSS:NICU: parental stress scale: neonatal intensive care unit

SD: standard deviation

parents should be prepared for this situation. This NICU hospitalization of their babies is such a complicated and unusual situation for parents. The fact that NICU babies are separated from their parents and in an intensive care environment is an unfamiliar and stressful situation for parents. ${ }^{17}$

\section{Findings related to the factors affecting the parents' PSS:NICU mean scores}

No significant differences were found between total stress scores of mothers and fathers in this study; however, it was determined that the total mean stress scores of mothers were higher than those of fathers. Having a premature baby causes stress for both parents. Recent studies have shown that mothers with premature infants hospitalized in neonatal intensive care units experience more stress than fathers. ${ }^{20,24,36}$ Mothers experience stress especially due to a sense of failure in the maternal role. ${ }^{24,36}$ Miles, Funk and Casper ${ }^{38}$ evaluated the stress conditions of 23 mothers and fathers with premature infants hospitalized in neonatal intensive care units. They found that scores of the mothers on the parental role alterations subscale were higher than the scores of the fathers. This difference could be explained by different views of parents on parenting roles. Fathers may think that their initial parenting roles will gradually increase from a lower level to a higher level. ${ }^{39}$

The results of the study indicated that the stress levels of parents with children other than the infants hospitalized in the intensive care unit were higher than those of parents with no other children. In this case, it was considered that parents had stress and felt guilty because they could not sufficiently care for their healthy children.

It is expected that parents of infants born at a younger gestational age and with a lower birth weight have more stress in the neonatal intensive care unit. No statistically significant difference was found between the mean scores of parents on the PSS:NICU in terms of gestational age and the birth weights of infants in our study. However, it was determined that mean scores on the PSS:NICU for parents with infants born at a younger gestational age and with a birth weight less than or equal to $1500 \mathrm{~g}$ were significantly higher. Raeside ${ }^{40}$ enrolled 12 mothers of premature infants in his study and found that the stress scores on the PSS:NICU for mothers with infants with a birth weight less than $1500 \mathrm{~g}$ were higher than those whose infants had a birth weight greater than 1500 g. ${ }^{40}$

The mean scores of parents on the PSS:NICU differed in terms of whether their infants were connected to respiratory equipment. The stress levels of parents with infants connected to respiratory equipment were higher.

Experiencing stressful life events can affect individuals positively and negatively. Individuals experiencing successive or intensive stressful life events may lose their power and experience 
a higher level of stress in a newer stressful life event. On the contrary, individuals with a history of previous stressful life event can apply the methods of coping with stress they previously developed to new stressful life events and thus overcome this condition. ${ }^{41}$ The higher stress levels of parents in this study who did not experience any stressful life events in the past year suggest that the parents had failed to derive positive outcomes from their previous experiences or they had lost their power due to such previous events.
The stress levels of parents who received information from different sources about the condition of their babies were found to be lower than the stress levels of those who did not. In the study carried out by Turan et al. ${ }^{4}$, parents were encouraged by nurses to receive information from different sources. It was determined at the end of the study that stress levels of parents who received information from different sources decreased. Knowledge acquisition is a strategy that reduces the fear and anxiety caused by obscurity. Knowledge

Table IV. Distribution of Parents' PSS:NICU Scores According to Factors that Affected Their. PSS: NICU Score Means.

\begin{tabular}{|c|c|c|c|c|}
\hline \multirow{2}{*}{ Variables } & \multicolumn{4}{|c|}{ PSS:NICU } \\
\hline & $\mathrm{n}$ & $\overline{\mathrm{x}}$ & SD & $P$ value \\
\hline \multicolumn{5}{|l|}{ Parents' age (years)* } \\
\hline $20 \downarrow$ & 10 & 108.00 & 34.59 & \multirow{4}{*}{$>0.05$} \\
\hline 20 to 29 & 32 & 109.75 & 26.56 & \\
\hline 30 to 39 & 30 & 108.93 & 39.81 & \\
\hline 40 and $\uparrow$ & 29 & 113.06 & 35.45 & \\
\hline \multicolumn{5}{|l|}{ Education* } \\
\hline Primary education & 32 & 121.25 & 20.34 & \multirow{3}{*}{$>0.05$} \\
\hline Middle/High school & 54 & 111.38 & 34.09 & \\
\hline University & 15 & 110.93 & 37.00 & \\
\hline \multicolumn{5}{|c|}{ Number of living children ${ }^{+}$} \\
\hline 1 & 61 & 110.36 & 31.59 & \multirow[t]{2}{*}{$<0.05$} \\
\hline 2 and $\uparrow$ & 40 & 120.67 & 29.21 & \\
\hline \multicolumn{5}{|c|}{ Infants' gestational age* } \\
\hline 24-28 weeks & 12 & 110.25 & 28.33 & \multirow{3}{*}{$>0.05$} \\
\hline 29-32 weeks & 25 & 117.48 & 32.32 & \\
\hline 33-37 weeks & 64 & 107.48 & 33.78 & \\
\hline \multicolumn{5}{|l|}{ Infants' birth weight ${ }^{+}$} \\
\hline $1500 \mathrm{~g} \leq$ & 34 & 120.94 & 24.73 & \multirow[t]{2}{*}{$>0.05$} \\
\hline $1500 \mathrm{~g}>$ & 67 & 104.88 & 36.54 & \\
\hline \multicolumn{5}{|l|}{ Age (days) ${ }^{+}$} \\
\hline $5-7$ & 47 & 120,63 & 30.42 & \multirow{2}{*}{$>0.05$} \\
\hline $8-10$ & 54 & 109,05 & 30.65 & \\
\hline \multicolumn{5}{|l|}{ NICU visits ${ }^{+}$} \\
\hline Everyday & 75 & 110,40 & 36.17 & \multirow[t]{2}{*}{$>0,05$} \\
\hline Two times a week & 26 & 109,96 & 26.31 & \\
\hline \multicolumn{5}{|c|}{ Mechanical ventilation $^{+}$} \\
\hline Yes & 33 & 126.48 & 23.73 & \multirow[t]{2}{*}{$<0.05$} \\
\hline No & 68 & 108.60 & 32.46 & \\
\hline \multicolumn{5}{|c|}{ Stressful life event last year ${ }^{+}$} \\
\hline Yes & 21 & 112.23 & 39.30 & \multirow[t]{2}{*}{$>0.05$} \\
\hline No & 80 & 109.77 & 32.44 & \\
\hline \multicolumn{5}{|c|}{ Received information about their babies ${ }^{+}$} \\
\hline Yes & 58 & 112.15 & 34.32 & \multirow[t]{2}{*}{$>0.05$} \\
\hline No & 43 & 116.13 & 25.92 & \\
\hline
\end{tabular}

PSS:NICU: parent stress scale: neonatal intensive care unit

SD: standard deviation

+Mann-Whitney U-test

*Kruskal-Wallis test 
acquisition also provides the opportunity to establish control over the situation, and it is a good way to reduce mothers' stress levels. Another study determined that parents' understanding of quality nursing care included predictions and provisions by nurses of information that parents may need and the establishment of a positive relationship between them for this purpose. ${ }^{42}$

Wigert et al. ${ }^{43}$ emphasized that it was important for nurses to understand parents' conditions and provide them with support in cases of need. They reported that it was relieving for parents to know that they were involved in the treatment of their babies even though they were not present physically. Parents should be provided with assistance to improve their selfesteem and confidence in neonatal intensive care units. Encouraging parents to visit their babies, teaching them how to care their babies and including them in decisions constitute foundations of this process. ${ }^{17,26}$

Parents may face specific stressors during the time their babies are hospitalized in a neonatal intensive care unit. Nurses provide information to and answer the questions of parents about the condition of their baby, provide them with emotional support and enable them to talk to and touch their baby. Medical treatments and practices employed must be explained while avoiding medical terms so that parents can understand. ${ }^{44}$

The limitation of our study is that our sample may not reflect global parents stress levels whose baby is hospitalized in the neonatal intensive care unit. This descriptive study was carried out in only one NICU. Additionally, since preterm infants are hospitalized for shortterm monitoring at the unit where the study is carried out, the stress level of parents could be evaluated in the first 10 days following the hospitalization of their premature baby. It is suggested that the new studies should be actualized by observing a higher number of newborn intensive care units, monitoring longer periods and analysing the effects of interventions on the stress levels of parents.

\section{REFERENCES}

1. Blencowe $\mathrm{H}$, Cousens $\mathrm{S}$, Oestergaard $\mathrm{MZ}$, et al. National, regional, and worldwide estimates of preterm birth rates in the year 2010 with time trends since 1990 for selected countries: a systematic analysis and implications. Lancet 2012; 379: 2162-2172.

2. Mwaniki MK, Atieno M, Lawn JE, Newton CR. Longterm neurodevelopmental outcomes after intrauterine and neonatal insults: a systematic review. Lancet 2012; 379: 445-452.

3. Mok E, Leung SF. Nurses as providers of support for mothers of premature infants. J Clin Nurs 2006; 15: 726-734.

4. Turan T, Basbakkal Z, Özbek S. Effect of nursing interventions on stressors of parents of premature infants in neonatal intensive care unit. J Clin Nurs 2008; 17: 2856-2866.

5. Gooding JS, Cooper LG, Blaine AL, Franck LS, Howse JL, Berns SD. Family support and family-centered care in the neonatal intensive care unit: origins, advances, impact. Semin Perinatol 2011; 35: 20-28.

6. Meijssen DE, Wolf MJ, Koldewijn K, Van Wassenaer AG, Kok JH, Van Baar AL. Parenting stress in mothers after very preterm birth and the effect of the Infant Behavioural Assessment and Intervention Program. Child Care Health Dev 2011; 37: 195-202.

7. Treyvaud K, Lee KJ, Doyle LW, Anderson PJ. Very preterm birth influences parental mental health and family outcomes seven years after birth. J Pediatr 2014; 164: 515-521.

8. Carter JD, Mulder RT, Bartram AF, Darlow BA. Infants in a neonatal intensive care unit: Parental response. Arch Dis Child Fetal Neonatal Ed 2005; 90: 109-113.

9. Miles MS, Holditch-Davis D. Parenting the prematurely born child: Pathways of influence. Semin Perinatol 1997; 21: 254-266.

10. Feeley N, Zelkowitz P, Cormier C, Charbonneau L, Lacroix A, Papageorgiou A. Post traumatic stres among mothers of very low birth weight infants at 6 months after discharge from the neonatal intensive care unit. Appl Nurs Res 2011; 24: 114-117.

11. Finlayson K, Dixon A, Smith C, Dykes F, Flacking R. Mothers' perceptions of family centered care in neonatal intensive care units. Sex Reprod Health 2014; 5: 119-124.

12. Heinemann A-B, Hellström-Westas L. Nyqvist KH Factors affecting parents' presence with their extremely preterm infants in a neonatal intensive care room. Acta Paediatr 2013; 102: 695-702.

13. Eriksson BS, Pehrsson G. Evaluation of psychosocial support to parents with an infant born preterm. J Child Health Care 2002; 6: 19-33.

14. Lau R, Morse CA. Parents coping in the neonatal intensive care unit: a theoretical framework. J Psychosom Obstet Gynaecol 2001; 22: 41-47.

15. Cimete G. Sorunlu yenidoğan ebeveynlerinin stresle baş etmelerini destekleyici bir hemşirelik yaklaşımı modeli. Türk Hemşireler Dergisi 1996; 46: 2-8. 
16. Gönülal D, Yalaz M, Altun-Köroğlu Ö, Kültürsay N. Both parents of neonatal intensive care unit patients are at risk of depression. Turk J Pediatr 2014; 56: 171-176.

17. Fowlie PW, Mchaffie H. Supporting parents in the neonatal unit. BMJ 2004; 329: 1336-1338.

18. Board R, Ryan-Wenger N. Stressors and stress symptoms of mothers with children in the PICU. J Pediat Nurs 2003; 18: 195-202.

19. Miles MS, Funk SG, Carlson J. Parental Stressor Scale: neonatal intensive care unit (PSS-NICU). Nurs Res 1993; 42: 148-152.

20. Franck LS, Cox S, Allen A, Winter I. Measuring neonatal intensive care unit related parental stress. J Adv Nurs 2005; 49: 608-615.

21. Montirosso R, Provenzi L, Calciolari G, Borgatti R; NEO-ACQUA Study Group. Measuring maternal stress and perceived support in 25 Italian NICUs. Acta Paediatr 2012; 101: 136-142.

22. Turan T, Başkale H, Öncel G. Determining the psychometric properties of the Turkish version of the nurse-parent support tool and the stres levels of parents of premature infants hospitalized in the neonatal intensive care unit. Clin Nurse Spec 2016; 30: $1-10$.

23. Chourasia N, Surianarayanan P, Adhisivam B, Bhat BV. NICU admissions and maternal stres levels. Indian J Pediatr 2013; 80: 380-384.

24. Matricardi S, Agostino R, Fedeli C, Montirosso R. Mothers are not fathers: differences between parents in the reduction of stres levels after a parental intervention in a NICU. Acta Paediatr 2013; 102: 8-14.

25. McGrath JM, Conliffe-Torres S. Integrating family centered developmental assessment and intervention in to routine care in the neonatal intensive care unit. Nurs Clin North Am 1996; 31: 367-386.

26. Erdem Y. Anxiety levels of mothers whose infants have been cared for in unit level-I of a neonatal intensive care unit in Turkey. J Clin Nurs 2010; 19: 1738-1747.

27. Cohen J. Statistical Power Analysis for The Behavioral Sciences, (2 ${ }^{\text {nd }}$ edition). New Jersey: Lawrence Erlbaum, 1988.

28. Turner M, Chur-Hansen A, Winefield H, Stanners M. The assessment of parental stress and support in the neonatal intensive care unit using the Parent Stress Scale-Neonatal Intensive Care Unit. Women Birth 2015; 28: 252-258.

29. Cano Giménez E, Sánchez-Luna M. Providing parents with individualised support in a neonatal intensive care unit reduced stress, anxiety and depression. Acta Paediatr 2015; 104: 300-305

30. Fotiou C, Vlastarakos PV, Bakoula C, Papagaroufalis K, Bakoyannis G, Darviri C, Chrousos G. Parental stress management using relaxation techniques in a neonatal intensive care unit: A randomised controlled trial. Intensive Crit Care Nurs 2016; 32: 20-28.
31. Turan T, Başbakkal Z. Study on validity and reliability of a Turkish version of the parental stress scale: Neonatal Intensive Care Unit. Journal of Hacettepe University School of Nursing 2006; 13: 32-42.

32. Shields-Poe D, Pinelli J. Variables associated with parental stress in neonatal intensive care units. Neonatal Netw 1997;16: 29-37.

33. Preyde M, Ardal F. Effectiviness of a parent "buddy" program for mothers of very preterm infants in a neonatal intensive care unit. CMAJ 2003; 168: 969973.

34. Cooke RJ, Griffin I. Altered body composition in preterm infants at hospital discharge. Acta Paediatr 2009; 98: 1269-1273.

35. Committee on Environmental Health. Noise: a hazard for the fetus and newborn. Pediatrics 1997; 100: 724727.

36. D'Souza SRB, Karkada S, Lewis LE, Mayya S, Guddattu V. Relationship between stress, coping and nursing support of parents of preterm infants admitted to tertiary level neonatal intensive care units of Karnataka, India: A cross-sectional survey. J Neonatal Nurs 2009; 15: 152-158.

37. Curley MAQ, Meyer EC. Caring practices: the impact of thecritical care experience on the family. Critical care nursing of infants and children (Ed.) Martha AQ Curley, Patricia A Moloney-Harmon. Philladelpia: Saunders, 2001.

38. Miles MS, Funk SG, Kasper MA. The stress response of mothers and fathers of preterm infants, Res Nurs Health 1992; 15: 261-269.

39. Lundqvist P, Westas LH, Hallström I. From distance to ward proximity: fathers lived experience of caring for their preterm infants. J Pediatr Nurs 2007; 22: 490-497.

40. Raeside L. Perceptions of enviromental stressors in the neonatal unit. Br J Nurs 1997; 6: 914-923.

41. Akşit S, Cimete G. Çocuğun yoğun bakım ünitesine kabulünde, annelere uygulanan hemşirelik bakımının ebeveynlerin anksiyete düzeyine etkisi. Cumhuriyet Üniversitesi Hemşirelik Yüksekokulu Dergisi 2001; 5: 25-36.

42. Price PJ. Parents' perceptions of the meaning of quality nursing care. Adv Nurs Sci 1993; 6: 33-41.

43. Wigert H, Dellenmark Blom M, Bry K. Parents' experiences of communication with neonatal intensivecare unit staff: an interview study. BMC Pediatr 2014; 14: 1-8.

44. Özyazıcıoğlu N, Tüfekci FG. Yenidoğan yoğun bakım ünitesinde bebekleri bakım alan annelerin kaygı ve umutsuzluk düzeylerini etkileyen faktörlerin incelenmesi. Atatürk Üniversitesi Hemşirelik Yüksekokulu Dergisi 2009; 12: 66-73. 